
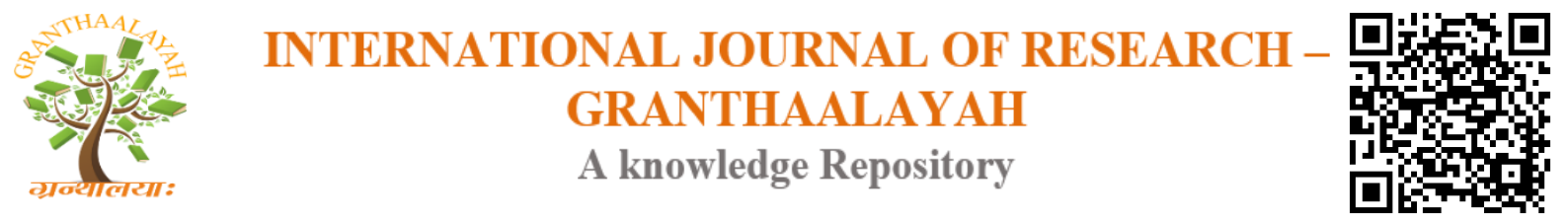

Science

\title{
KNOWLEDGE, ATTITUDES AND PRACTICES OF FARMERS TOWARDS PESTICIDES USE AND HANDLING IN GREENHOUSE FARMS, SUDAN
}

\author{
Awad O. Mohamed *1, Adam A. Mater 1, Ahmed M.A. Hammad 2, Abd Elaziz S.A. Ishag ${ }^{2}$ \\ Ali M. Eldein ${ }^{3}$, Elsadig M. Eltayeb ${ }^{4}$, Asia A. Dahab ${ }^{4}$, Ahmed Abdul Gader ${ }^{5}$, Azhari 0. \\ Abdelbagi ${ }^{2}$ \\ ${ }^{* 1}$ Department of Epidemiology, Faculty of Public Health, Alzeim Alazhari University, Sudan \\ ${ }^{2}$ Department of Crop Protections, Faculty of Agriculture, University of Khartoum, Khartoum, \\ SD 3114, Sudan \\ ${ }^{3}$ Department of Public Health, Faculty of Applied Medical Science, King Khalid University - \\ KSA \\ ${ }^{1,4}$ Department of Mother and Child Health, Directorate General of PHC, MoH, Khartoum, \\ Sudan \\ ${ }^{5}$ Department of Public health and environmental Studies, University of Khartoum, Khartoum, \\ Sudan
}

\begin{abstract}
A descriptive cross sectional study was carried out in Khartoum State to assess the knowledge, attitude, and practice of farmers towards pesticide residues on the vegetables grown in greenhouses. Fourteen farmers from seven localities of Khartoum State were selected and interviewed. The results revealed that majority of farmers $(92.9 \%)$ between the age of 25 and 45 years old, while only one farmer $(7.1 \%)$ was aging more than 45 years old. Regarding the educational level, the study showed that $20 \%$ were illiterates, whereas $40 \%$ had completed secondary high school, and $40 \%$ were university graduates. Almost $93 \%$ of them obtained training on pesticide use, handling, wear personal protective equipment and follow the instructions of the labels when using each pesticide. But unfortunately, $57 \%$ of them didn't know that the pesticide's residues can remain on the vegetables. Results also demonstrated that $92.8 \%$ of farmers showed poor practices regarding the disposal of empty pesticides containers. The study indicated that $71.4 \%$ of farmers were collecting their vegetables three days after spraying, while $28.6 \%$ were collecting after two days. These poor practices may lead to high concentration of pesticides' residues on the vegetables thus endangering the health of consumers.
\end{abstract}

Keywords: Knowledge; Attitudes; Practices; Pesticide residues; Greenhouse; Sudan.

Cite This Article: Awad O. Mohamed, Adam A. Mater, Ahmed M.A. Hammad, Abd Elaziz S.A. Ishag, Ali M. Eldein, Elsadig M. Eltayeb, Asia A. Dahab, Ahmed Abdul Gader, and Azhari O. Abdelbagi. (2018). "KNOWLEDGE, ATTITUDES AND PRACTICES OF FARMERS TOWARDS PESTICIDES USE AND HANDLING IN GREENHOUSE FARMS, SUDAN." 
[Mohamed et. al., Vol.6 (Iss.9): September 2018]

(Received: September 02, 2018 - Accepted: September 29, 2018)

International Journal of Research https://doi.org/10.5281/zenodo.1465024.
ISSN- 2350-0530(O), ISSN- 2394-3629(P)

DOI: 10.5281/zenodo.1465024

\section{Introduction}

Pesticides are widely used to protect vegetables from insect and diseases. Therefore, residues of pesticides affect consumer's health and there is concern over their carcinogenicity effect and toxicity [1]. On the other hands, pesticides are one of the most important components of high-input farming. Now humans have realized the extent to which pests harm crops, cause damage, and transmit diseases to both humans and domestic animals. The use of pesticides to control pests is not a new concept [2]. Igbedioh and other reported that environmental contamination and longterm health implications resulting from the intensive use of pesticides in agriculture, animal husbandry, and public health programs [3]. Fruits and vegetables are the most frequently consumed food group, which makes up $30 \%$ of food consumption on a mass basis the presence of pesticides in vegetables is a more serious health concern since they are consumed raw, without much processing and storage [4]. Human pesticide poisonings and illnesses are clearly the highest prices paid for all pesticide use [5]. Pesticide exposure can cause a variety of human health problems, both chronic and acute in both farmers and consumers. Chronic effects are typically the result of low levels of exposure over a long period of time even if there are no acute or immediate effects. Major health impacts from chronic exposure include cancers, reproductive and endocrine disruption, neurological damage, and immune system dysfunction [6, 7]. The WHO recommends that pesticides should use only when the benefits outweigh the risks, avoid cosmetic or scheduled use of pesticides in the home, use integrated pest management (IPM), non-chemical pest controls if pesticides are necessary. Store in original containers with child-proof seals, out of reach, in a locked cabinet, educate on the safe use of pesticides Follow manufacturer's instructions Use protective equipment [8]. For better production and aesthetic value, farmers are using a large number of insecticides during the entire period of growth of vegetables, even at fruiting stage and sometimes farmers also ignored the recommended waiting period between the harvest and last spray. Owing to this and other injudicious practice related to pesticide usage, pesticides become the inner part of vegetable in the shape of residues, which could be used by consumers thus creating health hazards $[9,10]$.

In Sudan, vegetables are grown extensively and constitute a large portion of the diet of the average Sudanese. It's were considered as protective supplementary foods as they contain large quantities of minerals, vitamins, and essential amino acids, which are required for normal functioning of the metabolic processes [11]. Sudan has a great potential to produce good quality fruits and vegetables. This is because of its large areas of fertile soil, abundant amount of water from rivers, rains, and underground water, suitable wide range of climate which allows variability of crops. Many types and cultivars of fruits and vegetables can be produced almost all the year round due to the climatic variations plus available land and water. This large potential could supply both local and export markets. The most important vegetables are onions and tomatoes followed by potatoes, okra, cucumbers, eggplant, water melons, pumpkins and a number of leafy vegetables. Vegetables are grown in small plots with pumped water including the national corporations such as Gezira Scheme where about 30,000 ha are devoted to vegetables [12]. Therefore, the objective of this study was to assess the knowledge, attitude, and practices of farmers towards the use of the 
pesticides and their residues and the safety measures taken by them during and after pesticides applications.

\section{Materials and Methods}

\section{Study Area/Setting}

Khartoum state vests the capital of Sudan and it is the largest state population wise. The estimated population of the state is 7, 413, 239 inhabitants. The state is administratively divided into seven localities. It is bordering Gazira and White Nile States in the south, Northern State and River Nile in the north, Gedaref and Kassala States in the east and North Kordufan in the west. Both Blue Nile and White Nile congregate to form the River Nile in the state. The population depends on government employment, trade and agriculture. Quite a sizable number of people migrate to the capital from all other states. The state is heavily busy with mixed farming along the Nile banks and in rural artificially irrigated huge areas. The usual diet in Khartoum depends very much on different varieties of vegetables which are mostly grown in Khartoum State and nearby areas of other states.

\section{Sample Size and Sampling Technique}

The desired sample size was calculated through the following equation:

$\mathrm{n}=\frac{\mathrm{N}}{1+\mathrm{e}(\mathrm{N}-1)}$

Where:

$\mathrm{n}=$ the required sample size

$\mathrm{N}=$ the total population (49 farms)

$\mathrm{e}=$ error allowed by using $(95 \%)$ confidence level $=0.05$.

by substituting the given values of $\mathrm{N}$ and $\mathrm{e}$ in the equation; then:

$\mathrm{n}=49 / 1+(0.05) *(49-1)=14.4$, by rounding then $\mathrm{n}=14$ farms

For distributing the desired sample size (selected farms between the localities of Khartoum state), the proportion according to the magnitude of each locality from the total population had been used as shown in Table1.

Table 1: Distribution of the Samples by Localities

\begin{tabular}{|l|l|l|}
\hline Locality & No. of Farms & No. of Samples \\
\hline Umbada & 17 & 5 \\
\hline Omdurman & 3 & 1 \\
\hline Karri & 2 & 1 \\
\hline Sharg Elneel & 5 & 1 \\
\hline Bahri & 12 & 3 \\
\hline Jabal Awliya & 8 & 2 \\
\hline Khartoum & 2 & 1 \\
\hline Total & 49 & 14 \\
\hline
\end{tabular}

All farms of each locality had been listed and given serial numbers, and then by using simple random sampling technique, 14 farms had been selected as shown in Table 2. 
Table 2: Selected Farms by Localities

\begin{tabular}{|l|l|}
\hline District & Farm Name \\
\hline Bahri & Khartoum Bank (Abu Haleima) \\
\hline Bahri & AlHai'a Al Arabia \\
\hline Bahri & Khartoum University \\
\hline Jebel Awliya & Ziyada \\
\hline Jebel Awliya & Mohamed Khidir \\
\hline Karari & Eltiseen \\
\hline Khartoum & Mohamed S.Elhag \\
\hline Sharq Elneel & Elzawaya \\
\hline Umbada & Elsha'er \\
\hline Umbada & Amir Mustafa \\
\hline Umbada & Younis Ahmed Younis \\
\hline Umbada & Mu'awia Elbirair \\
\hline Umbada & Mazin Esamu Eldein \\
\hline Umdorman & Elwalda \\
\hline
\end{tabular}

A structured questionnaire was used by the trained data collectors (Public Health Officers) to interview each of the 14 farmers. This was done in the farms and it took about 20 to 30 minutes.

\section{Data Management and Analysis}

\subsection{The Study Variables}

Background Information: Age, educational level and income per month besides types and names of pesticide used, Level of pesticide used, methods of pesticide application interval of pesticides spraying, periods of vegetable collection (pre-harvest period) after using pesticides and the practices of farmers regarding the protective measures taken during and after using pesticide and smoking, drinking and eating during pesticides use.

\subsection{Data and Samples' Collection Tools}

\section{The Team Had Used the Following Data Collection Tools}

Well-structured questionnaire of close ended and opened questions had been used for each farmer. The questionnaire had been tested during the training of the data collectors and the needed corrections in content or language had been inserted.

\section{The Data Collection Team Was Composed of the Following Persons}

Two data collectors: two public health officers filled the structured questionnaire.

A supervisor: a senior public health officer who supervised and monitored the data collectors and revised the questionnaires to ensure that all questions had been answered and filled properly.

\section{Training of Data Collectors}

Data collectors were selected carefully from the public health officers who have experience and a senior public health officer was assigned as a supervisor. 
All data collectors and the supervisor have been trained for two days theoretically and practical on the contents of the questionnaire and field test of the questionnaire.

\subsection{Data Entry and Analysis}

All filled questionnaires have been checked and revised by the supervisor and then the data have been entered and analysed by an expert statistician using SPSS software version 16.

Tables and charts have been used to present the results. Chi-square tests had been used to examine the relationship between independent variables and the outcomes of interest in the bi-variants analysis. The results of the relationship with $\mathrm{P}<0.05$ were considered statistically significant.

\section{Results and Discussions}

The study revealed that the majority of farmers (92.9\%) were between the age group of 25 to 45 years old while only one farmer $(7.1 \%)$ was aging more than 45 years old. These findings are in consistent with a similar study in Kuwait conducted by Jallow et al [13] found out that the majority of the farmers $(69.70 \%)$ interviewed were between 21 and 40 years old, with the average age being 29.8 years. Slightly more than $9 \%$ of the farmers were 50 years and over. Also in India, Lavanya and Giridhar [14] reported that a large percentage (43.3\%) of the participants was aged between 36 and 45 years [2]. Similar results were also found by other researchers in Nepal and Brazil [15, 16].

Table 3: Age groups of farmers in Khartoum State, $(\mathrm{N}=14)$

\begin{tabular}{|l|l|l|}
\hline Age group & Frequency & Percent \\
\hline 25-45 years & 13 & 92.9 \\
\hline More than 45 years & 1 & 7.1 \\
\hline Total & 14 & 100.0 \\
\hline
\end{tabular}

This study revealed that $20 \%$ of workers were illiterates, $40 \%$ completed their secondary high school, and $40 \%$ were university graduates. These findings are better than [18] which found a considerable number of the farmers $(16.8 \%)$ were illiterate or had not completed elementary education, $69.2 \%$ had completed either elementary or secondary education, and $14 \%$ were which found a considerable number of the farmers $(16.8 \%)$ were illiterate or had not completed elementary education, $69.2 \%$ had completed either elementary or secondary education, and $14 \%$ were educated to a tertiary level. In Brazil, almost half of respondents (49.1\%) had not completed primary education, and $(6.3 \%)$ were illiterate or had never attended school [18] while in the United States 55.8\% of pesticide applicators in New York State had at least 12 years of schooling [19]. However, educated farmers are more knowledgeable about pesticide safety, have a better ability to read, understand and follow hazard warnings on labels, and conceptualized the consequences of poor pesticide usage practices [20]. 


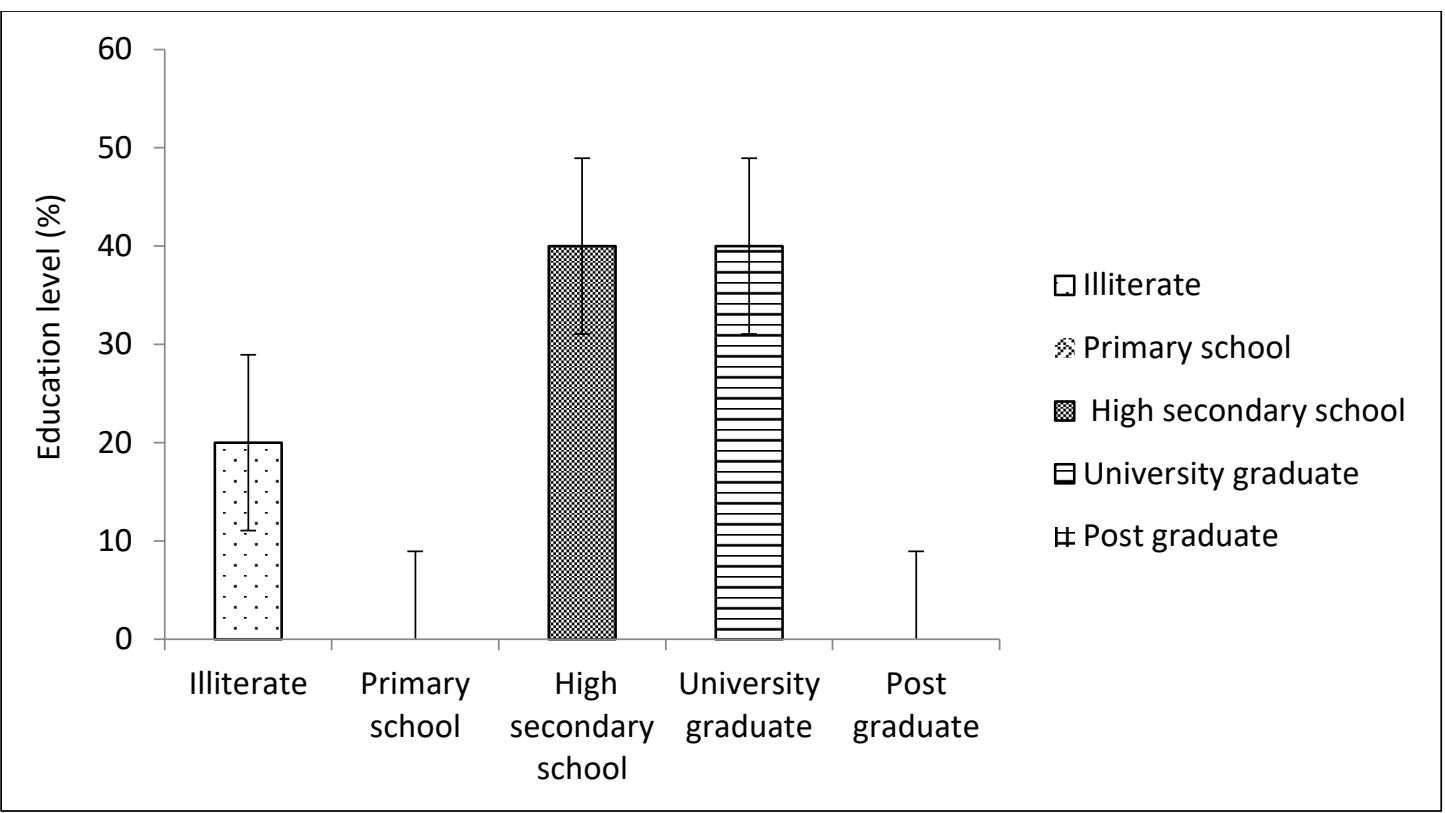

Figure 1: Farmer's Education levels in Khartoum State Distributed by localities, $(\mathrm{N}=14)$

This study found that cucumber is cultivated in all (100\%) selected farms during the period of the study while tomato was cultivated by only $35.7 \%$ of the selected farms in three localities namely: Umbada, Khartoum, and Bahri. When asked about the reasons for not cultivating the tomatoes, the majority (64.3\%) of the farmers said that the cultivation cost of the tomato in greenhouse was very high at that time, plus the tomato of the open field farms was available in the market with the affordable cost to the consumers.

Table 4: Types of vegetables grown in the selected farms by Localities, $(\mathrm{N}=14)$

\begin{tabular}{|l|l|l|l|l|l|l|l|l|}
\hline \multirow{2}{*}{ Locality } & \multicolumn{2}{|c|}{} & \multicolumn{2}{|c|}{} & \multicolumn{3}{l|}{$\mid$} \\
\cline { 2 - 10 } & Frequency & $\mathbf{\%}$ & Frequency & $\mathbf{\%}$ & Frequency & $\mathbf{\%}$ & Frequency & $\boldsymbol{\%}$ \\
\hline Omdurman & 1 & 7.1 & 0 & 0.0 & 1 & 7.1 & 1 & 7.1 \\
\hline Umbada & 5 & 35.7 & 3 & 21.4 & 0 & 0.0 & 0 & 0.0 \\
\hline Karari & 1 & 7.1 & 0 & 0.0 & 0 & 0.0 & 0 & 0.0 \\
\hline Khartoum & 1 & 7.1 & 1 & 7.1 & 0 & 0.0 & 0 & 0.0 \\
\hline Jabal awlia & 2 & 14.3 & 0 & 0.0 & 2 & 14.3 & 0 & 0.0 \\
\hline Bahari & 3 & 21.4 & 1 & 7.1 & 0 & 0.0 & 0 & 0.0 \\
\hline Sharg alneel & 1 & 7.1 & 0 & 0.0 & 0 & 0.0 & 0 & 0.0 \\
\hline Total & $\mathbf{1 4}$ & $\mathbf{1 0 0 . 0}$ & $\mathbf{5}$ & $\mathbf{3 5 . 7}$ & $\mathbf{3}$ & $\mathbf{2 1 . 4}$ & $\mathbf{1}$ & $\mathbf{7 . 1}$ \\
\hline
\end{tabular}

The study also revealed that $85.7 \%$ of farmers knew that pesticides were very harmful to the environment and human health, while only $2(14.3 \%)$ said that pesticides are moderate harmful. These findings are consistent with Juliana et al study [21] which found that $90 \%$ of the farmers considered pesticides harmful to the health, especially to those who apply the pesticides or work on the farm ( $81.3 \%$ and $70.5 \%$, respectively); only one-third considered that the health of those living near the plantation area could be impaired by pesticides. The findings agree with Kuwait study [13] which reported that although most farmers agreed that pesticide use poses some risk to 
human health (71\%) and the environment (65\%), they also indicated that pesticides were indispensable for high crop yield (80\%).

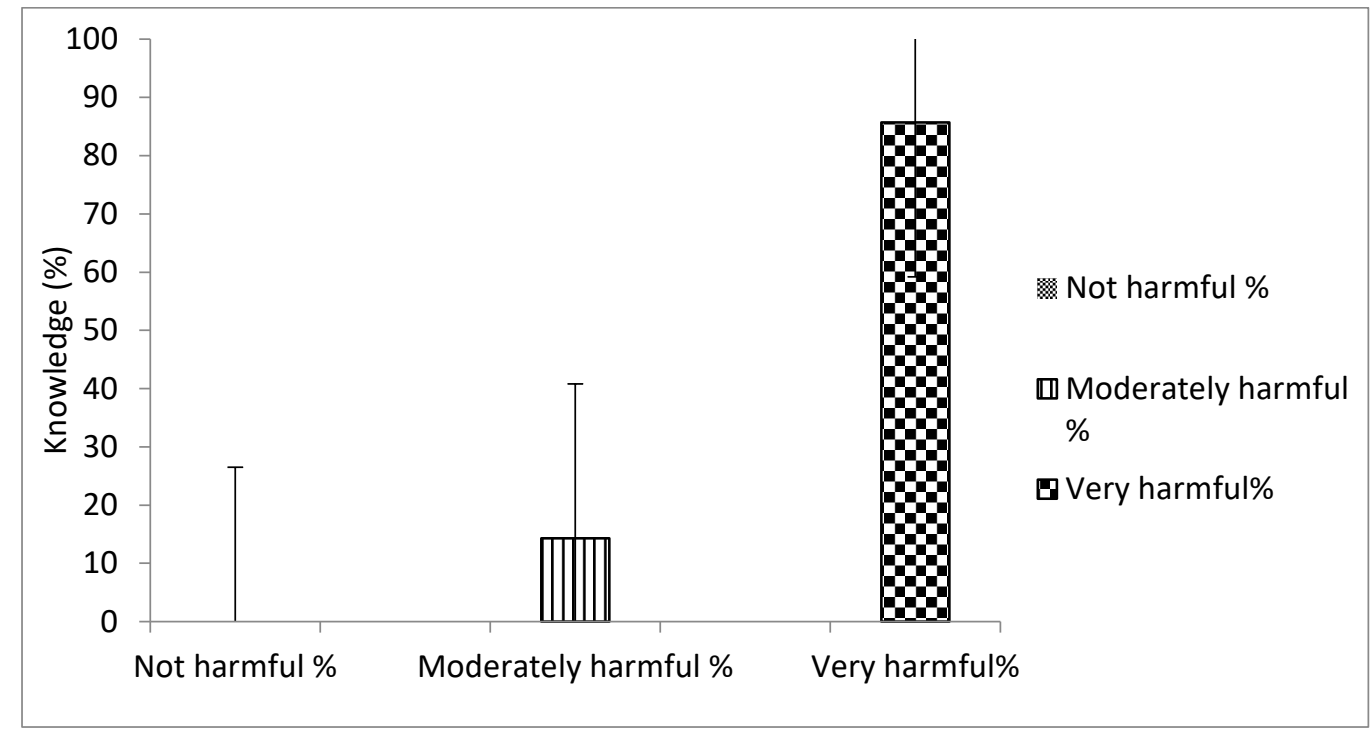

Figure 2: Knowledge of Farmers Regarding Harmfulness of Pesticides ( $\mathrm{N}=14)$

In this study, all (100\%) farmers were using insecticides and fungicides and one of them was found using herbicides in addition to the insecticides and fungicides; these findings were similar to Zawiyah [1] who indicated that insecticides were used by $98 \%$ of the farmers, followed by bactericides $(79 \%)$, nematicides $(24 \%)$, and herbicides $(5 \%)$. When asked about the source of these pesticides, almost half of farmers $(50 \%)$ mentioned that they purchased these pesticides from pesticide companies, and $42.9 \%$ purchased theirs from the local markets and one farmer $(7.1 \%)$ didn't answer. These findings are in consistent with Brazil Study [18] which found most of the farmers purchased the pesticide products at the local cooperative $(56.4 \%)$.

Table 5: Types of pesticides used by Farmers of Greenhouses

\begin{tabular}{|l|l|l|l|l|l|l|l|l|}
\hline \multirow{2}{*}{ Locality } & & \multicolumn{2}{|l|}{} & \multicolumn{2}{l|}{$\mid$} & \\
\cline { 2 - 10 } & Frequency & $\%$ & Frequency & $\%$ & Frequency & $\%$ & Frequency & $\%$ \\
\hline Omdurman & 1 & 7.1 & 0 & 0.0 & 1 & 7.1 & 1 & 7.1 \\
\hline Umbada & 5 & 35.7 & 1 & 7.1 & 5 & 35.7 & 5 & 35.7 \\
\hline Karari & 1 & 7.1 & 0 & 0.0 & 1 & 7.1 & 1 & 7.1 \\
\hline Khartoum & 1 & 7.1 & 0 & 0.0 & 1 & 7.1 & 1 & 7.1 \\
\hline Jebel Awlia & 2 & 14.3 & 0 & 0.0 & 2 & 14.3 & 2 & 14.3 \\
\hline Bahri & 3 & 21.4 & 0 & 0.0 & 3 & 21.4 & 3 & 21.4 \\
\hline Sharq Elneel & 1 & 7.1 & 0 & 0.0 & 1 & 7.1 & 1 & 7.1 \\
\hline Total & 14 & $\mathbf{1 0 0 . 0}$ & 1 & $\mathbf{7 . 1}$ & 14 & $\mathbf{1 0 0 . 0}$ & $\mathbf{1 4}$ & $\mathbf{1 0 0 . 0}$ \\
\hline
\end{tabular}

Most $(72 \%)$ of the farmers in this study stated that they had worked in vegetable business for 110 years; $21 \%$ worked less than 1 year while only $7 \%$ worked for more than 10 years. A similar study [1] revealed that most of the respondents (68\%) had 5-10 years of farming experience, and $10.4 \%$ having more than 10 years of farming experience. Also in Brazil, Juliana et al [21] reported 
that most of the respondents $(76.8 \%)$ had been using pesticides for at least 5 years, and $21.4 \%$ for over 20 years.

Table 6: How long the farmer been in vegetable business

\begin{tabular}{|l|l|l|l|l|l|l|l|l|}
\hline \multirow{2}{*}{ Locality } & \multicolumn{2}{|l|}{ Less than 1 year } & \multicolumn{2}{l}{$\mathbf{1}-\mathbf{1 0}$ years } & \multicolumn{2}{l}{$\begin{array}{l}\text { More than } \\
\text { years }\end{array}$} \\
\cline { 2 - 11 } & Frequency & $\%$ & Frequency & $\%$ & Frequency & $\%$ & \multicolumn{2}{l|}{ Total } \\
\hline Omdurman & 0 & 0.0 & 1 & 7.1 & 0 & 0.0 & 1 & 7.1 \\
\hline Umbada & 1 & 7.1 & 4 & 28.6 & 0 & 0.0 & 5 & 35.7 \\
\hline Karari & 1 & 7.1 & 0 & 0.0 & 0 & 0.0 & 1 & 7.1 \\
\hline Khartoum & 0 & 0.0 & 0 & 0.0 & 1 & 7.1 & 1 & 7.1 \\
\hline Jebel Awlia & 0 & 0.0 & 2 & 14.3 & 0 & 0.0 & 2 & 14.3 \\
\hline Bahri & 0 & 0.0 & 3 & 21.4 & 0 & 0.0 & 3 & 21.4 \\
\hline $\begin{array}{l}\text { Sharq } \\
\text { Elneel }\end{array}$ & 0 & 0.0 & 1 & 7.1 & 0 & 0.0 & 1 & 7.1 \\
\hline Total & $\mathbf{2}$ & $\mathbf{1 4 . 3}$ & $\mathbf{1 1}$ & $\mathbf{7 8 . 6}$ & $\mathbf{1}$ & $\mathbf{7 . 1}$ & $\mathbf{1 4}$ & $\mathbf{1 0 0 . 0}$ \\
\hline
\end{tabular}

Pesticide residue refers to the pesticide that may remain on, or in the food crops [22]. However, this study revealed that the majority $(57.1 \%)$ of the farmers didn't know that the pesticides residues may remain on vegetables after the application and most of them were in the farms of Umbada and Bahri localities, while $42.9 \%$ knew that the pesticides residues remained on vegetables. These findings disagreed with Brazil study which found that most farmers $(67 \%)$ agreed that pesticide residues remained in the food after treatment and about $40 \%$ of these acknowledged that the amount remaining in the food for consumption depends on the withholding period [21].

Table 7: Knowledge of farmers about the pesticides residues on vegetables after the application of Pesticides

\begin{tabular}{|l|c|c|c|c|c|c|}
\hline \multirow{2}{*}{ Locality } & \multicolumn{2}{|c|}{ Yes } & \multicolumn{2}{c|}{ No } & \multicolumn{2}{c|}{ Total } \\
\cline { 2 - 7 } Omdurman & Frequency & $\%$ & Frequency & $\%$ & Frequency & $\%$ \\
\hline Umbada & 0 & 0.0 & 1 & 7.1 & 1 & 7.1 \\
\hline Karari & 3 & 21.4 & 2 & 14.3 & 5 & 35.7 \\
\hline Khartoum & 0 & 0.0 & 1 & 7.1 & 1 & 7.1 \\
\hline Jebel Awlia & 2 & 14.3 & 0 & 0.0 & 2 & 14.3 \\
\hline Bahri & 1 & 7.1 & 2 & 14.3 & 3 & 21.4 \\
\hline Sharq Elneel & 0 & 0.0 & 1 & 7.1 & 1 & 7.1 \\
\hline Total & $\mathbf{6}$ & $\mathbf{4 2 . 9}$ & $\mathbf{8}$ & $\mathbf{5 7 . 1}$ & $\mathbf{1 4}$ & $\mathbf{1 0 0 . 0}$ \\
\hline
\end{tabular}

The majority (92.9\%) of the farmers of this study were found using the pesticides according to the packet/bottle label while $35.7 \%$ mentioned that they are using the pesticides according to both the packet/bottle label and the engineer's instructions. These findings disagree with the study in Bangladesh which found that only $23 \%$ of applicators follow instructions written on bottles or packets, while some $(39 \%)$ apply them according to the prescriptions from pesticide traders and depending on the criteria of the fields described by the farmers [20]. The study also disagrees with the Kuwait study which reported that over $70 \%$ of the farmers did not read or follow instructions on pesticide labels because they were unable to read and/or understand the meaning of the labels 
(56\%), the labels were written in English (a foreign language to them) (35\%), and the instructions were too long and complicated (45\%). Slightly more than $15 \%$ of the farmers indicated that the font sizes on the labels were too small to easily read. Only $28 \%$ of the farmers were able to read, understand, and follow pesticide label instructions correctly [13]. Also, Fikre et al [23] in Ethiopia reported that more than $30 \%$ of the farmers used pesticides without a label or instruction on its container; and less than $40 \%$ of the farmers understood the signs on the pesticide container. Likewise, around $(60 \%)$ have bought pesticides containing instructions in languages that farmers are not familiar with. Only $30 \%$ of the farmers can read the label or instructions on the containers. This together with the low level of education in the study area could result in using chemicals that are not appropriate for a specific service [23].

Table 8: Level of pesticides used as mentioned by Farmers of the Greenhouses

\begin{tabular}{|l|l|l|l|l|l|l|l|l|}
\hline \multirow{2}{*}{ Locality } & \multicolumn{2}{|c|}{$\begin{array}{c}\text { According to } \\
\text { Packet/bottle } \\
\text { label }\end{array}$} & \multicolumn{2}{|c|}{$\begin{array}{c}\text { According to } \\
\text { engineer's } \\
\text { instructions }\end{array}$} & $\begin{array}{c}\text { According to } \\
\text { pesticide } \\
\text { seller's } \\
\text { instructions }\end{array}$ & \multicolumn{2}{c|}{ Total } \\
\cline { 2 - 10 } & Frequency & $\%$ & Frequency & $\%$ & Frequency & $\%$ & Frequency & $\%$ \\
\hline Omdurman & 1 & 7.1 & 0 & 0.0 & 0 & 0 & 1 & 7.1 \\
\hline Umbada & 5 & 35.7 & 2 & 14.3 & 0 & 0 & 5 & 35.7 \\
\hline Karari & 0 & 0.0 & 1 & 7.1 & 0 & 0 & 1 & 7.1 \\
\hline Khartoum & 1 & 7.1 & 0 & 0.0 & 0 & 0 & 1 & 7.1 \\
\hline Jebel Awlia & 2 & 14.3 & 1 & 7.1 & 0 & 0 & 2 & 14.3 \\
\hline Bahri & 3 & 21.4 & 1 & 7.1 & 0 & 0 & 3 & 21.4 \\
\hline $\begin{array}{l}\text { Sharq } \\
\text { Elneel }\end{array}$ & 1 & 7.1 & 0 & 0.0 & 0 & 0 & 1 & 7.1 \\
\hline Total & $\mathbf{1 3}$ & $\mathbf{9 2 . 9}$ & $\mathbf{5}$ & $\mathbf{3 5 . 7}$ & $\mathbf{0}$ & $\mathbf{0}$ & $\mathbf{1 4}$ & $\mathbf{1 0 0 . 0}$ \\
\hline
\end{tabular}

Regarding the interval of pesticides spraying, it was found that $42.9 \%$ of the farmers sprayed the pesticides twice a week, $35.7 \%$ sprayed once a week while $21.4 \%$ of them sprayed day after day. A similar study in Bangladesh found that on an average of 4\%, 19\%, 18\% and 58\% of respondents spray pesticides over their vegetable fields in each day, alternative day, two and one times in a week respectively [24].

Table 9: Interval of pesticides spraying as mentioned by farmers

\begin{tabular}{|l|l|l|}
\hline Spraying interval & Frequency & Percent \\
\hline Day after day & 3 & 21.4 \\
\hline Once a week & 5 & 35.7 \\
\hline Twice a week & 6 & 42.9 \\
\hline Total & $\mathbf{1 4}$ & $\mathbf{1 0 0 . 0}$ \\
\hline
\end{tabular}

For the period of vegetables collection after spraying the pesticides (pre-harvest interval), the study revealed that the majority $(71.4 \%)$ of the farmers were collecting their vegetables three days after spraying of the pesticides, while $28.6 \%$ were collecting their vegetables two days after spraying of the pesticides. It was found in Bangladesh study, nearly three-fourths (72\%) of the total respondents do not know about the regulation of vegetables collection while $27 \%$ of them do not 
follow the label of instruction though they are aware that they should do it. In addition, almost half $(47 \%)$ of the farmers usually collect vegetables after three days of using pesticides, though harvesting time varies with vegetable types, 3\%, 8\%, $12 \%$ and $30 \%$ of farmers have been marketing vegetables on the same day, the next day, two days later and three days later, after using pesticides, respectively [24]. These practices in our study were implemented by the farmers for all vegetables irrespective to the label instructions of each insecticide, and this might increase the level of pesticides residues which risks the health of the consumers. Similar practices were further reported in Ghana study [8] which demonstrated that most vegetable farmers harvest their produce within 7 days after spraying pesticides with some harvesting their produce on the same day after spraying, thereby endangering the lives of consumers. Also, Amoako et al [25] reported that the majority of cabbage farmers in the Ejisu-Juaben Municipality of the Ashanti Region of Ghana continue spraying pesticides during produce harvesting, hence no waiting period is observed, thereby exposing consumers to high pesticide residue levels [10].

Moreover, there was a significant association between frequencies of sprays as mentioned by farmers and harvest period after spray $(\mathrm{X} 2=7.637, \mathrm{P}=0.012)$ and according to this result, those farmers who were spraying their vegetables more frequently, and harvested their vegetables in a shorter period, may lead to high concentration of pesticides' residues on the vegetables. However, this study revealed no significant association between farmers' education levels and the frequency of the pesticides spray $\left(\mathrm{X}^{2}=4.876, \mathrm{P}=0.326\right)$; also no significant association between farmer's education level and harvest period interval (HPI) after pesticide spray $(\mathrm{X} 2=4.657, \mathrm{P}=0.091)$.

Table 10: Period of vegetables collection after spraying the pesticides

\begin{tabular}{|l|l|l|}
\hline Harvest period & Frequency & Percent \\
\hline Two days after spraying & 4 & 28.6 \\
\hline Three days after spraying & 10 & 71.4 \\
\hline Total & $\mathbf{1 4}$ & $\mathbf{1 0 0 . 0}$ \\
\hline
\end{tabular}

By wearing protective clothing and using available safety devices such as face masks, goggles, and gloves, the danger from contamination by pesticides can be minimized [26]. This study showed the good practices of farmers regarding the use of personal protective equipment (PPE) to protect themselves from the exposure of pesticides as all (100\%) farmers mentioned that they are using PPE during pesticides spraying and all of them (100\%) are washing their hands and faces after spraying the pesticides. These findings are in agreement with Matthews [27] who indicated that the use of appropriate PPE, such as coveralls, and the adoption of other protective measures and good personal hygiene, such as showering, not smoking, eating or drinking while handling pesticides are considered good practices to reduce occupational pesticide exposure; also our findings agree with Keifer [28] which reported that an increase in the use of protective measures decreases the probability of poisoning by $44 \%$ to $80 \%$, whereas lack of PPE use increases the potential of dermal and respiratory exposure to pesticides [29]. Similarly, Schenker et al. [30] found that $93 \%$ of California farmers wore personal protective equipment when handling pesticides, which was considerably higher than farmers in other areas of the USA. However, the findings of this study disagree with Ethiopia study which reported nearly $42 \%$ of farmers had never used any PPE to protect themselves against pesticide exposure [31]. It also disagrees with the study of Juliana et al. [21] which found almost all farmers (99.1\%) considered the use of PPE necessary during pesticide application, but almost half (48.2\%) did not use them properly, and 7.2\% never 
used them at all. Gloves were never used by about $18 \%$ of the farmers, and impermeable clothes were used by only $18.8 \%$ of the farmers. Also, Recena et al. [16] observed that the majority of the farmers in MS wore hats, but less than half wore boots, masks, gloves or impermeable clothing; and in Thailand, Jintana et al. [32] reported that $64.4 \%$ of farmers did not use any type of PPE during their work, similar to what was found by Karunamoorthi et al. [20] in Ethiopia (76.3\%).

Table 11: Protection measures taken by farmers during pesticides spraying

\begin{tabular}{|c|c|c|c|c|c|c|c|c|c|c|c|c|}
\hline \multirow[b]{2}{*}{ Locality } & \multicolumn{2}{|c|}{ Overalls } & \multicolumn{2}{|c|}{ Gloves } & \multicolumn{2}{|c|}{ Eye glasses } & \multicolumn{2}{|c|}{ Face mask } & \multicolumn{2}{|c|}{ Boots/shoes } & \multicolumn{2}{|c|}{ Total } \\
\hline & $\begin{array}{l}\text { Frequ } \\
\text { ency }\end{array}$ & $\%$ & $\begin{array}{c}\text { Frequ } \\
\text { ency }\end{array}$ & $\%$ & $\begin{array}{c}\text { Frequ } \\
\text { ency }\end{array}$ & $\%$ & $\begin{array}{c}\text { Frequ } \\
\text { ency }\end{array}$ & $\%$ & $\begin{array}{l}\text { Frequ } \\
\text { ency }\end{array}$ & $\%$ & $\begin{array}{c}\text { Frequ } \\
\text { ency }\end{array}$ & $\%$ \\
\hline Omdurman & 1 & 7.1 & 1 & 7.1 & 1 & 7.1 & 1 & 7.1 & 1 & 7.1 & 1 & 7.1 \\
\hline Umbada & 5 & 35.7 & 5 & 35.7 & 5 & 35.7 & 5 & 35.7 & 5 & 35.7 & 5 & 35.7 \\
\hline Karari & 1 & 7.1 & 1 & 7.1 & 1 & 7.1 & 1 & 7.1 & 1 & 7.1 & 1 & 7.1 \\
\hline Khartoum & 1 & 7.1 & 1 & 7.1 & 1 & 7.1 & 1 & 7.1 & 1 & 7.1 & 1 & 7.1 \\
\hline $\begin{array}{l}\text { Jebel } \\
\text { Awlia }\end{array}$ & 2 & 14.3 & 2 & 14.3 & 2 & 14.3 & 2 & 14.3 & 2 & 14.3 & 2 & 14.3 \\
\hline Bahri & 3 & 21.4 & 3 & 21.4 & 3 & 21.4 & 3 & 21.4 & 2 & 14.3 & 3 & 21.4 \\
\hline $\begin{array}{l}\text { Sharq } \\
\text { Elneel }\end{array}$ & 1 & 7.1 & 1 & 7.1 & 1 & 7.1 & 1 & 7.1 & 1 & 7.1 & 1 & 7.1 \\
\hline Total & 14 & 100 & 14 & 100 & 14 & 100 & 14 & 100 & 13 & 92.9 & 14 & 100 \\
\hline
\end{tabular}

This study revealed unsafe practices of disposing of empty pesticides containers as the majority of the farmers (78.6\%) were found disposing of the empty pesticide containers by burning them, $7.1 \%$ throwing them in the open space and $7.1 \%$ buried them while $7.1 \%$ is using others means of disposal. These findings are like findings of Kuwait study [25] when disposing of empty pesticide containers, the majority of respondents adopted unsafe behaviors such as discarding, incinerating or burying containers on-farm. Similarly, in Mato Grosso do Sul (MS), Bigatão [24] reported that $34.8 \%$ of the farmers burned or buried the pesticide containers. These unsafe behaviors and practices may lead to environmental contamination and a risk to human health and have been reported as a major problem in several studies [10-11].

However, the Environmental Health Manual [11] identifies the community rubbish dump as the best place to discard empty pesticides containers after being washed three times with the appropriate solvent. The manual again warned against the burning of pesticides containers because they can give off poisonous gases. 


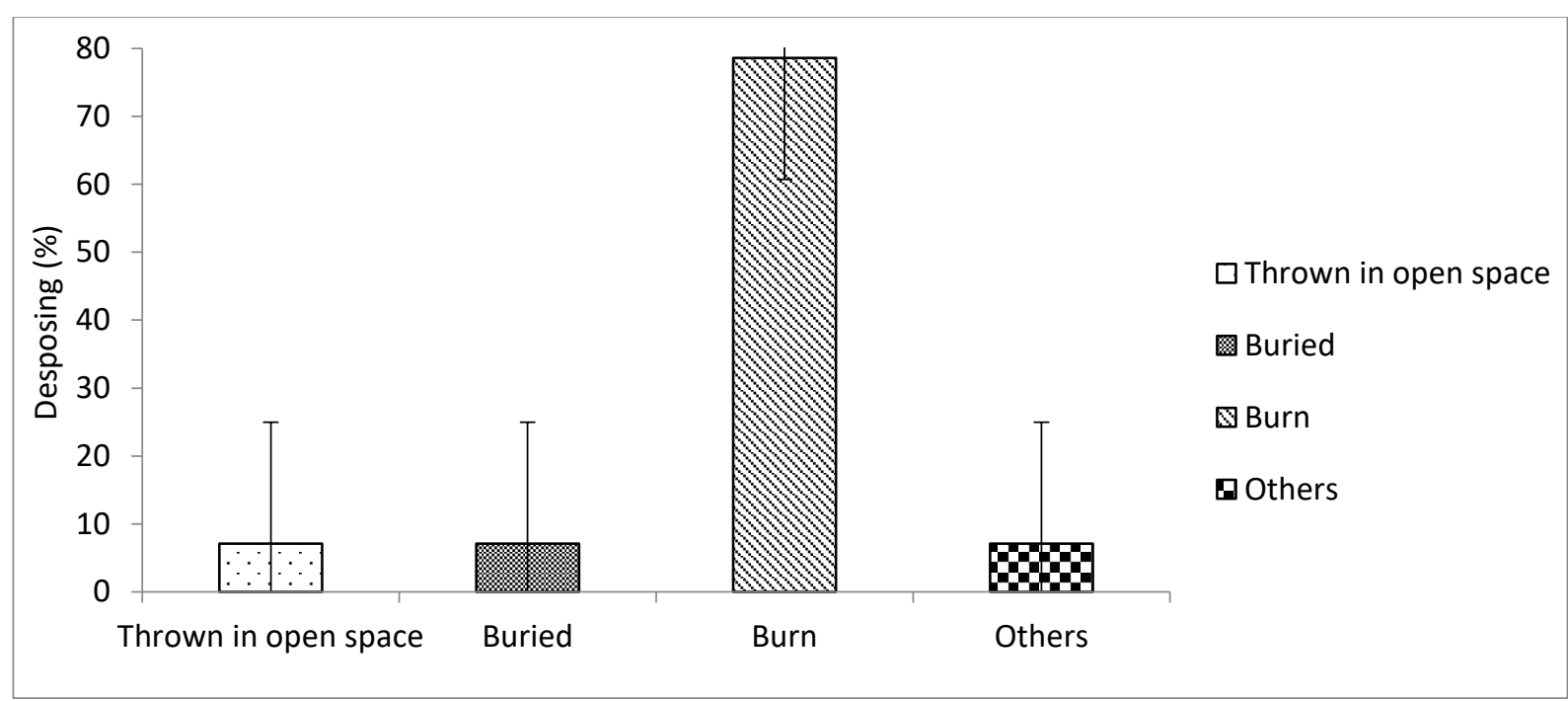

Figure 3: Disposal methods of pesticides containers $(\mathrm{N}=14)$

In respect to the training of the farmers on pesticides use and handling, the present study indicated that $92.9 \%$ of the farmers have received training on pesticides use and handling from either Ministry of Health or Ministry of Agriculture, while only 7.1\% denied answering. These findings disagreed with Kuwait study [13] which revealed that $64 \%$ of the farmers did not receive any training or technical support on the judicious use and safe handling of pesticides, while $36 \%$ were trained. Uganda study [9] revealed that approximately one third (31\%) of the farmers have had training on how to use and handle pesticides. Also in North Gaza, Bassam et al. [12] had reported that $29 \%$ of the farmers said that they attended training courses in various agricultural topics, where pesticides were part of the training material. While $71 \%$ of the farmers pointed out that they have never attended such training courses nor were invited to those activities.

Table 12: Training of the farmers of Greenhouses

\begin{tabular}{|l|l|l|l|l|l|l|l|l|}
\hline \multirow{2}{*}{ Locality } & Yes & No & \multicolumn{2}{l|}{ No answer } & \multicolumn{2}{l|}{ Total } \\
\cline { 2 - 10 } & Frequency & $\mathbf{\%}$ & Frequency & $\mathbf{\%}$ & Frequency & $\mathbf{\%}$ & Frequency & $\%$ \\
\hline Omdurman & 1 & 7.1 & 0 & 0 & 0 & 0 & 1 & 7.1 \\
\hline Umbada & 5 & 35.7 & 0 & 0 & 0 & 0 & 5 & 35.7 \\
\hline Karari & 1 & 7.1 & 0 & 0 & 0 & 0 & 1 & 7.1 \\
\hline Khartoum & 1 & 7.1 & 0 & 0 & 0 & 0 & 1 & 7.1 \\
\hline Jebel Awlia & 2 & 14.3 & 0 & 0 & 0 & 0 & 2 & 14.3 \\
\hline Bahri & 3 & 14.3 & 0 & 0 & 0 & 0 & 3 & 21.4 \\
\hline Sharq Elneel & 1 & 7.1 & 0 & 0 & 0 & 0 & 1 & 7.1 \\
\hline Total & $\mathbf{1 4}$ & $\mathbf{1 0 0}$ & $\mathbf{0}$ & $\mathbf{0}$ & $\mathbf{0}$ & $\mathbf{0}$ & $\mathbf{1 4}$ & $\mathbf{1 0 0}$ \\
\hline
\end{tabular}

\section{Conclusions and Recommendations}

The study concluded that there is a great risk results from unsafe handling of pesticides on environmental and human health because most of the farmers were not following the recommended withdrawal period, not knowing that pesticides residues may remain on vegetable and were not taking the necessary measures to protect themselves, consumers and environment and recommended to Ministry of Agriculture and Ministry of Health should conduct training 
courses to the farmers of the greenhouses to raise their awareness regarding the pesticides residues, proper disposal of pesticides empty containers, and the importance of the pre-harvest period and Integrated Pesticide's Management methods (IPM), as well as the importance of proper hygiene practices and use of personal protective equipment (PPE) when handling pesticides.

\section{Acknowledgements Themselves}

We are very thankful to data collectors, their supervisor and all farmers who participated in this study.

\section{Conflict of Interest}

The authors have declared no conflict of interest.

\section{References}

[1] Zawiyah S, Che Man Y.B., Nazimah H., Chin C. K., Tsukamoto I., Hamanyza A. H. And Norhaizan I. (2007). "Determination of Organochlorine and Pyrethroid Pesticides in Fruit and Vegetables Using Sax/Psa Clean-Up Column”. Food Chem., 102, 98-103.

Doi: 10.1016/J.Foodchem.2006.05.003.

[2] Harris Jeremy (2000). "Biopesticides Series 1 Chemical Pesticide Markets", Health Risks and Residues-Cabi Pub (2000)

[3] Igbedioh Sylvester (1991). "Effects of Agricultural Pesticides on Humans, Animals and Higher Plants in Developing Countries". Archives of Environmental Health, 46(4), 218-224. Doi/Abs/10.1080/00039896.1991.9937452.

[4] Leo Nollet And Hamir Rathore (2009). "Handbook of Pesticides Methods of Pesticide". Residues Analysis-Crc Press.

[5] Who (2003). "Gems/Food Regional Diets" (Regional Per Capita Consumption of Raw and SemiProcessed Agricultural Commodities).

[6] Epa (1977). “Minutes of Administrator's Pesticide Policy Advisory Committee”, Washington, Dc, Us Environmental Protection Agency

[7] Moses Marion (1999). "Pesticides Killers in Our Midst", In Nair K P. (Eds) Warning: Pesticides Are Dangerous to Your Health, (Penang: Pesticide Action Network Asia And the Pacific, 1999). (Iosr-Jestft), E-Issn: 2319-2402, P- Issn: 2319-2399. Volume 8, Issue 1 Ver. V (Feb. 2014), Pp 5767.

[8] Who (2008). "Training for The Health Sector" (Pesticides) Who. Geneva

[9] Oesterlund Anna, Thomsen Jane, Deogratias Sekimpi, Maziina James, Racheal Apio And Jørs Erik. (2018). "Pesticide Knowledge, Practice and Attitude and How It Affects the Health of Small-Scale Farmers in Uganda": A Cross-Sectional Study." African Health Sciences 14(2), 420-433. Http://Dx.Doi.Org/10.4314/Ahs.V14i2.19.

[10] Osborne Penny, Xu Zichun, Swanson Kenneth, Walker Thia, And Farmer Delphine. (2015). "Dicamba and 2, 4-D Residues Following Applicator Cleanout: A Potential Point Source to The Environment and Worker Exposure". Journal of The Air and Waste Management Association, 65(9), 1153-1158. Doi/Abs/10.1080/10962247.2015.1072593.

[11] Environmental Health Manual (2010). "Disposal of Unused Pesticides and Empty Pesticide Container", 2010. Available Online At:

Http://Www.Health.Gov.Au/Internet/Publications/Publishing.Nsf/Content/Ohp-Enhealth-ManualAtsicnt-I-Ch5. Accessed 20 July 2015 
[12] Al-Zain Bassam And Mosalami Jihad. (2014). "Pesticides Usage, Perceptions, Practices and Health Effects Among Farmers in North Gaza, Palestine”. Indian Journal of Applied Research, 4(6), 1722. Doi: $10.15373 / 2249555 x / J u n e 2014 / 5$.

[13] Jallow Mustapha, Awadh Dawood, Albaho Mohammed, Davi Vimala And Thomas Binson. (2017). "Pesticide Knowledge and Safety Practices Among Farm Workers in Kuwait: Results of A Survey.” Ed. Mohamed-Bassem A. Ashour. International Journal of Environmental Research and Public Health 14(4), 340. Doi: 10.3390/Ijerph14040340.

[14] Lavanya Kumari And Giridhar Reddy. (2013). "Knowledge and Practices of Safety Use of Pesticides Among Farm Workers, India. Iosr". Journal of Agriculture and Veterinary Science. 6(2), 01-08.

[15] Atreya Kishor. (2007). "Pesticide Use Knowledge and Practices: Gender Differences In Nepal". Environmental Research 104(2), 305-311. Doi: 10.1016/J.Envres.2007.01.001.

[16] Recena Maria, Caldas Eloisa, Pires Dario And Pontes Elenir. (2006). "Pesticides Exposure in Culturama, Brazil-Knowledge, Attitudes, And Practices”. 2006. Environmental Research 102(2), 230-236. Doi: 10.1016/J.Envres.2006.01.007.

[17] Pan-Uk. (2003). "Current Pesticide Spectrum", Global Use and Major Concerns. Http: //Www.Pan-Uk.Org/Briefing/Sida_Fil/Chap1.Htm (January 18, 2003).

[18] Stokes Lynette, Stark Alice, Marshall Elizabeth, Narang Amarjit. (1995). Neurotoxicity Among Pesticide Applicators Exposed to Organophosphates. Occupational and Environmental Medicine 52, 648-653. Doi: 10.1136/Oem.52.10.648.

[19] Karunamoorthi Kaliyaperumal, Mohammed Mubarek And Wassie Fantahun. (2012). "Knowledge and Practices of Farmers with Reference to Pesticide Management": Implications on Human Health. Archives of Environmental \& Occupational Health. 67, 109-116.

Doi.Org/10.1080/19338244.2011.598891.

[20] Pasiani Juliana, Torres Priscila, Silva Juciê, Diniz Bruno And Calada Eloisa. (2012). "Knowledge, Attitudes, Practices and Biomonitoring of Farmers and Residents Exposed to Pesticides in Brazil", International Journal of Environmental Research and Public Health, 9(9), 3051-3068. Doi: 10.3390/Ijerph9093051.

[21] Iupac (2006). "Compendium of Chemical Terminology", 2nd Ed. (The "Gold Book") (1997). Online Corrected Version: (2006) "Pesticide Residue".

[22] Ocho Fikre, Abdissa Fikadu, Yadessa Gezahegn And Bekele Adunga. (2016). "Smallholder Farmers' Knowledge, Perception and Practice in Pesticide Use in South Western Ethiopia”. Journal of Agriculture and Environment for International Development. 110 (2), 307-323.

Doi.Org/10.12895/Jaeid.2016110.484.

[23] Sheikh Jewel, Hoque Abdul, Paul Alak And Rahman Arifur. (2014). "Unsafe Use of Pesticide and Its Impact on Health of Farmers": A Case Study in Burichong Upazila, Bangladesh. Iosr Journal of Environmental Science, Toxicology and Food Technology. 8(1), 57-67.

[24] Amoako Pk, Patick Kumah, Appiah Francis. (2012). "Pesticides Usage in Cabbage (Brassica Oleracea) Cultivation in The Ejisu-Juaben Municipality of The Ashanti Region of Ghana". International Journal of Research in Chemistry and Environment 2, 26-31.

[25] Pimentel David. (2005). "Environmental and Economic Costs of The Application of Pesticides Primarily in The United States" Environment, Development and Sustainability. 7(2), 229-252. Doi 10.1007/978-94-007-7796-5_2.

[26] Matthews Graham. (2008). "Attitudes and Behaviors Regarding Use of Crop Protection ProductsA Survey of More Than 8500 Smallholders In 26 Countries". Crop Protection. 27(3-5), 834-846. Doi: 10.1016/J.Cropro.2007.10.013.

[27] Keifer Matthew. (2000). "Effectiveness of Interventions in Reducing Pesticide Overexposure and Poisonings". American Journal of Preventive Medicine 18(4), 80-89. Doi.Org/10.1016/S07493797(00)00144-6. 
[28] Wesseling, Catharina, Partanen Timo, Mcconnell Rob And Hogstedt Chriter. (1997). Agricultural Pesticide Use in Developing Countries: Health Effects and Research Needs. International Journal of Health Services. 27(2), 273-308. Doi.Org/10.2190/E259-N3ah-Ta1y-H591.

[29] Schenker Marc, Orenstein Marla., Samuels Steven. (2002). "Use of Protective Equipment Among California Farmers". American Journal of Preventive Medicine. 42, 455-464. Doi: 10.1002/Ajim.10134.

[30] Gesesew Hhailay, Woldemichael Kifle, Massa Desalegn And Mwanri Lillian. (2016). "Farmers Knowledge, Attitudes, Practices and Health Problems Associated with Pesticide Use in Rural Irrigation Villages, Southwest Ethiopia". Plos One 11(9), E0162527.

[31] Sirivarasai Jintana, Kaojarern Sming, Yoovathaworn Krongtong And Sura Thanyachai. (2009). "Cholinesterase Activity, Pesticide Exposure and Health Impact in A Population Exposed to Organophosphate". International Archives of Occupational and Environmental Health. 82(7), 833842. Doi: 10.1007/S00420-009-0422-9.

*Corresponding author.

E-mail address: awadomer51@ hotmail.com 